\title{
Agressividade e empatia na infância: Um estudo correlacional com pré-escolares ${ }^{1}$
}

\author{
Michelle Girade Pavarino \\ Almir Del Prette \\ Zilda A. P. Del Prette \\ Universidade Federal de São Carlos
}

\begin{abstract}
RESUMO
A agressividade está associada a vários problemas no desenvolvimento infantil, com evidências de correlação inversa com a empatia que é vista como um possível inibidor de tais comportamentos. Com base no referencial das Habilidades Sociais, este estudo avalia as diferenças na freqüência de comportamentos empáticos e agressivos de crianças pré-escolares, sob situações estruturadas de demandas para tais desempenhos. Participaram 28 crianças, de 4 a 6 anos, de ambos os sexos. Os dados foram coletados por filmagem, com registro posterior de freqüência dos diferentes tipos de comportamento empáticos e agressivos. Os resultados não apontaram correlação entre os dois conjuntos nem diferenças associadas à idade ou sexo, embora a maior proporção de comportamentos empáticos tenha sido uma tendência em todas as faixas etárias. São apresentados dados qualitativos dos tipos de comportamentos empáticos e agressivos associados à idade. Discutem-se as implicações do presente trabalho para a pesquisa na área e para a educação infantil.
\end{abstract}

Palavras-chave: empatia; agressividade; pré-escolares; habilidades sociais; prevenção.

\begin{abstract}
Aggressiveness and empathy in the childhood: A correlational study with pre-school children

Aggressiveness is associated to several problems in the child development, with evidences of inverse correlation with empathy that is seen as a possible inhibitor of such behaviors. Based in the referential of the Social Skills, this study evaluates the differences in the frequency of empathic and aggressive behaviors of preschool children, under structured situations demanding such actings. The participants were 28 children, from 4 to 6 years, of both sexes. The data were collected by recording, with subsequent registration of frequency of the different types of empathic and aggressive behavior. The results did not show correlation between the two groups nor differences associated to age or sex, although a greater proportion of empathic behaviors was a tendency in all of the age groups. Qualitative data concerning the types of empathic and aggressive behaviors associated to age groups are presented. The implications of the present work for the research in the area and for child education are discussed.
\end{abstract}

Keywords: empathy; aggressiveness; preschoolers; social abilities; prevention.

Um dos desafios presentes no processo da Educação Infantil e que vem merecendo atenção de diversas áreas da ciência, dedicadas à interação social, comportamento humano e educação, é a agressividade na infância. Isso vem acontecendo por sua íntima ligação com fatores de risco ao desenvolvimento e à aprendizagem. As pesquisas vêm mapeando ocorrências, variáveis e correlação de fatores que envolvem o comportamento agressivo (Del Prette \& Del Prette, 2003; McEvoy \& Walker, 2000; Walker \& Sprague, 1999).
Apesar da complexidade na definição de agressão, por seu significado cultural, a maior parte dos pesquisadores concorda em definir o comportamento antisocial, tal como o agressivo, como aquele com intenção de produzir dano a outra pessoa (Bandura, 1977; 1986; Caprara, Barbaranelli, Incatasciato, Pastorelli, \& Rabasca, 1997; Del Prette \& Del Prette, 2003; Marinho, 2003; Patterson, Reid \& Dishion, 1992). Tal comportamento pode se manifestar muito cedo na infância, com várias características que apresentam conseqüências negativas para o desenvolvimento do 
indivíduo, mesmo quando não se mantém ao longo do ciclo vital.

A interação organismo-ambiente tem peso fundamental nas reações agressivas, sob diferentes contingências, com os desdobramentos negativos posteriores da violência amplamente reconhecidos, não obstante controvérsias quanto à base empírica de sua estabilidade (Kazdin \& Buela-Casal, 1997; Walker, Colvin \& Ramsey, 1995).

Ao longo de décadas, estudos transversais e longitudinais vêm apontando diferentes fatores associados ao comportamento anti-social agressivo. Características cognitivas (tais como distorções nas habilidades de solução de problemas, predisposição a atribuir intenções hostis aos demais, ressentimento e suspeita) e outros fatores de risco (por exemplo, baixa inteligência, violência familiar, isolamento social, rejeição da criança, abusos, fracasso escolar, desvantagens socioeconômica, discriminação social e cultural) apresentamse associados, bem como problemas de atenção, hiperatividade e dificuldades acadêmicas. Além disso, observa-se manifestação de relacionamento interpessoal empobrecido e comprometimento do desenvolvimento socioemocional por conseqüência da freqüente rejeição por pares e de déficit em habilidades sociais (Bjoerkqvist \& Oesterman, 2000; Ciccarone, 1997; Del Prette \& Del Prette, 2001; Del Prette \& Del Prette, 2002; Garcia, 2001; Kazdin, 1993; Marinho, 2003; Nowicki \& Duke, 1989; Roscoe, 1980; Walker $\&$ Severson, 2002).

Associadas às estratégias para controle de comportamentos antissociais, podem-se verificar propostas de desenvolvimento socioemocional visando ampliar os fatores protetores dos problemas de agressividade. Destaca-se, aqui, a importância atribuída ao desenvolvimento de valores e comportamentos prósociais, especialmente de empatia (Del Prette \& Del Prette, 2001; 2003).

A empatia, enquanto uma das subclasses de habilidades sociais, engloba três aspectos fundamentais em sua definição: o cognitivo, o afetivo e o comportamental. Sob esse enfoque, ela se caracteriza como a capacidade de apreender sentimentos e de identificarse com a perspectiva do outro, manifestando reações que expressam essa compreensão e sentimento (Del Prette \& Del Prette, 1999; Falcone 1998/2001; Goldstein \& Michaels, 1985; Roberts \& Strayer, 1996; Garcia-Serpa, Meyer \& Del Prette, 2003). A expressão "situação de demanda afetiva", pode ser incorporada a essa definição, sugerindo uma propriedade de algumas situações que sistematicamente eliciam respostas empáticas (Del Prette \& Del Prette, 2001).
Tais demandas, conforme Del Prette e Del Prette (2001), são consequiências da vida em sociedade, reguladas pela cultura de subgrupos, que sinalizam ocasião ou oportunidade na qual se espera um desempenho social específico em relação a uma ou mais pessoas. A habilidade social empática é aprendida, exercitada, e consolidada na interação social e é particularmente importante, pois o responder empaticamente às pessoas facilita o estabelecimento de vínculos interpessoais (Garcia-Serpa, Meyer \& Del Prette, 2003; Hops, 1983; Planalp, 1999).

$\mathrm{O}$ controle do impulso de reação imediata à comunicação do interlocutor, a concentração na visão e sentimentos deste, a observação de sinais não verbais presentes na comunicação, o controle da defensividade, paciência, sinceridade e disposição para ouvir são fatores importantes para o desenvolvimento da habilidade empática (Araújo \& Del Prette, 2000). Nesse sentido, os déficits de empatia estão associados a um conjunto de outros fatores cognitivos e afetivos, tais como distorções perceptivas, problemas de regulação e autocontrole emocional (Covell \& Scarola, 2002; Geer, Estupinan \& Manguno-Mire, 2000).

A violência e a agressividade envolvem déficit de empatia do agressor na medida em que, ao produzir intencionalmente dano ao outro, este não se sensibiliza nem reconhece o medo ou pavor desse outro (Del Prette \& Del Prette, 2003). Embora a empatia seja considerada como produto evolutivo do modo de organização familiar dos seres humanos e animais, aparecendo desde a mais tenra idade, o seu desenvolvimento depende primariamente das condições de socialização da criança no contexto familiar. Se esse ambiente não for favorável, ou a criança experienciar negligência ou abusos, podem ocorrer os déficits de empatia, que facilitam o comportamento agressivo (Emery, 1989; Main \& George, 1985).

A maior parte das pesquisas examinadas na literatura sobre a empatia teve, como sujeitos, crianças em idade escolar de ambos os sexos, observando-se diferenças de comportamentos entre meninas e meninos que foram atribuídas à educação e aos valores da cultura (Domitrovich \& Bierman 2001; Garcia, 2001). Homens e mulheres acabam assumindo estereótipos de gênero, apresentando um repertório comportamental limitado a certos padrões e transmitem isso aos filhos (Ickes, 1997). Outro ponto significativo é que, em crianças em idade escolar, observa-se uma relação inversa entre os comportamentos empáticos e agressivos (Bjoerkqvist \& Oesterman, 2000; Ciccarone, 1997; Garcia, 2001; Nowicki \& Duke, 1989; Roscoe, 1980). Os déficits da empatia refletem, portanto, um contexto inadequado de socialização e educação, des- 
tacado pela insuficiente oportunidade de aprendizagem de comportamentos, valores culturais de não violência e habilidades sociais de resolução de problemas interpessoais para lidar com a própria agressividade e a do outro (Del Prette \& Del Prette, 2005a).

A ampliação do conhecimento sobre os fatores associados ao desenvolvimento da empatia em crianças pode, portanto, contribuir para o aperfeiçoamento de programas de prevenção à violência, se entendida como possível inibidor deste problema.

Desde o nascimento, o indivíduo está predisposto a emitir sinais socioemocionais e a responder a sinais dos outros, de modo que tais condutas podem lhe assegurar a sobrevivência, desenvolvendo-se em um continuum ao longo da sua existência (Brazelton, 1994; Hops, 1983; Novak, 1996; Thompson, 1987). Como o primeiro ambiente de interação dos indivíduos, depois do familiar, é a escola, é neste que deverão ser complementados o desenvolvimento das habilidades sociais, incluindo a aquisição e refinamento dos comportamentos empáticos. Se as crianças não exibem tais comportamentos nesses ambientes, duas hipóteses são possíveis: a) as crianças não dispõem dessas habilidades em seu repertório; b) as demandas para tais comportamentos são escassas ou inexistentes em tais ambientes. Portanto, muitas vezes é necessário criar situações estruturadas para a avaliação do desempenho social das crianças. Além disso, como a agressividade e a empatia constituem classes amplas de comportamentos, a análise desses desempenhos implica identificar comportamentos específicos que delas fazem parte.

As pesquisas na literatura nacional sobre estudos que enfocam empatia e agressividade praticamente inexistem, constatando-se uma carência de produção científica nessa área. Por outro lado, observa-se um volume muito grande de investigações em outros países, com a crescente aplicabilidade dos conhecimentos produzidos, tanto no tratamento quanto na prevenção dos diferentes problemas do desenvolvimento infantil, evidenciando a importância dessa temática. Embora muitos dados dessas pesquisas possam ser utilizados, eles não constituem parâmetros seguros sobre a relação entre empatia e agressividade no contexto cultural brasileiro. Com base nessas considerações, o objetivo deste trabalho foi o de investigar a possível correlação entre comportamentos agressivos e comportamentos empáticos de crianças pré-escolares em situações estruturadas de demandas para isso e características desses comportamentos associadas a sexo e idade.

\section{MÉTODO}

\section{Participantes}

Participaram deste estudo 28 crianças, matriculadas em uma escola do sistema municipal de ensino de uma cidade do interior do Estado de São Paulo, compondo um grupo de 13 meninas (três de quatro anos, quatro de cinco e seis de seis anos) e outro de 15 meninos (cinco de quatro, quatro de cinco e seis de seis anos). As crianças foram selecionadas por sorteio pelos seus professores, que informaram sobre a ocorrência e a frequiência dos comportamentos, agressivos e empáticos, apresentados por seus respectivos alunos. Os participantes foram identificados por meio de siglas com duas letras e um número. A primeira letra representa a inicial do nome da criança; a segunda o sexo (A para meninas e $\mathrm{O}$ para meninos), seguida da representação da idade pelos números 4 (quatro anos), 5 (cinco anos) ou 6 (seis anos). Por exemplo: BA4 Beatriz (nome fictício), menina, quatro anos de idade.

A coleta de dados foi realizada nas dependências da instituição de ensino, em salas de aula destinadas para a realização desta pesquisa.

\section{Instrumentos e Materiais}

Roteiros de vivências. Com base em Del Prette e Del Prette (2001), foram elaborados quatro roteiros de vivência que incluíam: título da vivência, material a ser utilizado, procedimentos e observação. As vivências tinham o objetivo de criar situações, razoavelmente semelhantes às experimentadas pelos participantes, duas com demandas para autocontrole da agressividade e duas para a emissão de comportamentos empáticos. As vivências com demandas para autocontrole envolviam situações competitivas que previam vencedores e perdedores e foram nomeadas de "Jogos das peças coloridas" e "O desenho gigante". As vivências com demandas para comportamentos empáticos receberam as denominações de "O animal carente" e "A boneca chorona".

Equipamento de filmagem. Utilizou-se uma câmera VHS, posicionada estrategicamente no local da coleta de dados, de modo a tornar possível a filmagem dos episódios e interferir o mínimo possível na rotina do ambiente escolar.

Protocolos de Observação. Foram elaborados dois Protocolos de Observação, para serem utilizados durante as vivências, destinados a registro, respectivamente, de comportamentos agressivos e de compor- 
tamentos empáticos. Os protocolos continham indicações para preenchimento do nome da professora e do aluno, freqüência de subclasses de comportamentos agressivos e empáticos, número de alunos participantes da vivência e espaço para observações adicionais. As categorias de comportamentos agressivos e empáticos foram definidas previamente com base em outras utilizadas em pesquisas sobre o tema (Del Prette \& Del Prette, 2000).

Formulário de Avaliação do Professor ou TRF (Teacher Report Form). Desenvolvido por Achenbach e Edelbrock (1991), trata-se de um formulário em que o professor avalia a competência social e os problemas de comportamento de crianças e adolescentes de quatro a dezoito anos. Esse instrumento prevê, também, a coleta de informações sobre: idade, sexo, ano de escolaridade, tempo de conhecimento e convivência do professor com o aluno, desempenho escolar atual, comparação com crianças da mesma idade em termos de esforço, adequação de comportamento, aprendizagem e, principalmente, 113 afirmações sobre comportamentos da criança, às quais o professor responde com base em uma escala de três pontos: zero (Não verdadeira), um (Algumas vezes verdadeira) e dois (Freqüentemente verdadeira).

\section{Procedimento de coleta de dados}

Após a seleção dos participantes, foi realizada uma reunião com os pais e/ou responsáveis com a finalidade de explicar os objetivos da pesquisa, metodologia a ser utilizada e também oferecer os esclarecimentos, visando obter a assinatura do TCLE (Termo de Consentimento Livre e Esclarecido) para a participação de seus filhos, sendo, na ocasião, adotados todos os cuidados éticos pertinentes.

A coleta de dados por meio das quatro vivências, teve duração média de vinte minutos cada e todas foram filmadas. Para essa etapa, as 28 crianças foram subdivididas em três grupos de mesma faixa etária, sendo que cada grupo experienciou as quatro situações de vivências.

A coleta de dados junto aos professores foi realizada na sala dos professores da escola ou em suas residências. Os três professores participantes foram soli- citados a responder individualmente ao instrumento, um para cada aluno, em presença do pesquisador que deu uma instrução inicial e ficou à disposição para eventuais dúvidas quanto ao entendimento das questões do TRF.

\section{Tratamento de dados}

Os registros dos comportamentos agressivos e empáticos obtidos por observação foram organizados em planilhas de frequiência para a amostra total e para as subamostras por sexo e idade. As 28 fichas do TRF, preenchidas pelos professores, foram digitalizadas em um programa de computador que acompanha o instrumento (Programa ADM) e que registra os dados obtidos, classificando a criança quanto aos problemas emocionais apresentados. Neste estudo foram utilizadas somente as informações relativas à frequiência de comportamentos agressivos que foram organizados em planilhas do SPSS por faixa etária e por sexo.

Os dados de frequiência dos comportamentos empáticos e agressivos obtidos por meio de observação e do TRF foram objeto de análise estatística descritiva (média e desvio-padrão para o grupo total e para os subgrupos de sexo e idade) e de análise das diferenças entre os subgrupos por sexo (teste t) e idade (ANOVA), adotando-se $\mathrm{p}<0,05$. Também foram realizadas análises de correlação (Pearson) para verificar o nível de dependência entre as variáveis.

\section{RESULTADOS}

Os resultados gerais da observação direta em situação estruturada de vivências indicaram uma maior proporção de comportamentos empáticos (Média = $6.0 ; \mathrm{dp}=3.37$ ) do que agressivos (Média $=4.9, \mathrm{dp}=$ 5.81) associados às situações de demandas respectivas. No entanto, cabe salientar a grande variabilidade tanto na freqüência de comportamentos empáticos (de 1 a 15) como agressivos (de 0 a 20), evidenciada pelo desvio-padrão que foi ainda maior para os comportamentos agressivos.

A comparação entre meninos e meninas, na frequiência de comportamentos empáticos e agressivos, é ilustrada na Figura 1. 


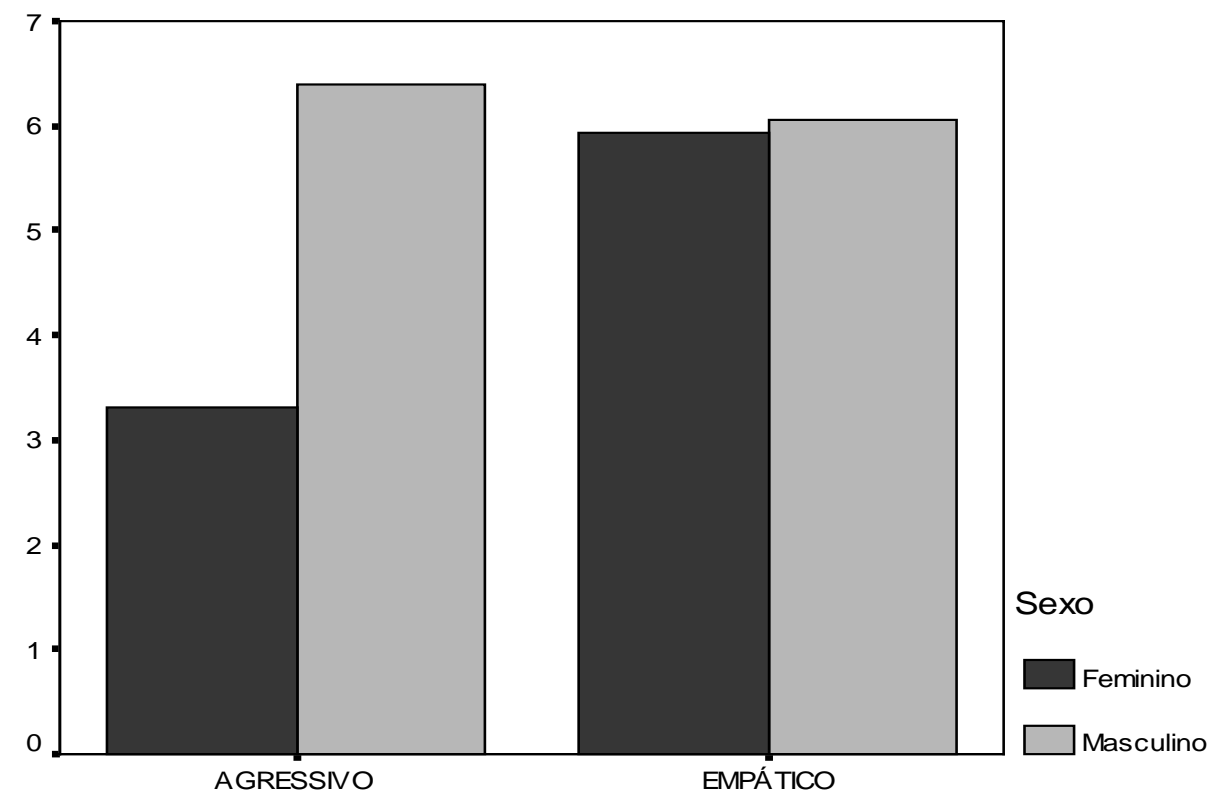

Figura 1. Freqüência média de comportamentos agressivos e empáticos, conforme o sexo, registradas nas situações estruturadas de vivências.

Embora nominalmente as meninas tenham apresentado freqüência média mais alta para comportamentos empáticos e os meninos para agressivos, essa diferença não se mostrou significativa. No entanto, quando se considerou a proporção de comportamen- tos agressivos e empáticos de cada criança, as diferenças ficaram muito próximas da significância, revelando uma tendência de maior proporção de agressivos entre meninos e maior proporção de empáticos entre as meninas, conforme se verifica na Tabela 1 .

Tabela 1. Dados de comparação entre meninos e meninas nos comportamentos agressivos e empáticos registrados nas vivências

\begin{tabular}{cccccccc}
\hline Classe & Sexo & $\mathrm{N}$ & Média & D. Padrão & $\mathrm{t}$ & $\mathrm{df}$ & $\mathrm{P}$ \\
\hline \multirow{2}{*}{ Agressivo } & Feminino & 13 & 25,231 & 26,388 & $-1,994$ & 26 &, 057 \\
Agressivo & Masculino & 15 & 45,266 & 26,623 & $-1,995$ & 25,500 &, 057 \\
Empático & Feminino & 13 & 74,769 & 26,388 & 1,987 & 26 &, 058 \\
& Masculino & 15 & 54,800 & 26,643 & 1,988 & 25,506 &, 058 \\
\hline
\end{tabular}

A proporção de comportamentos agressivos e empáticos registrados para cada um dos meninos e meninas é ilustrada na Figura 2. 


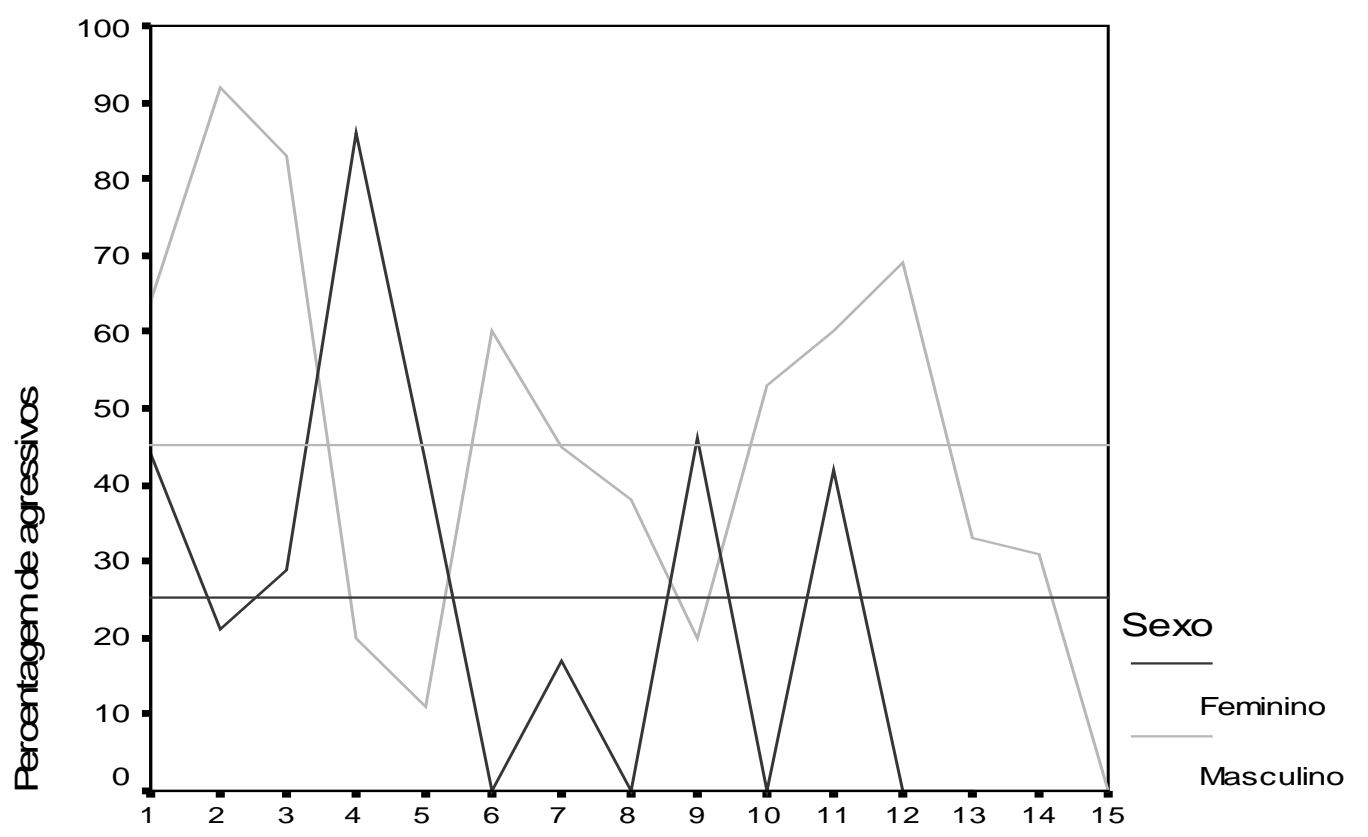

Figura 2. Comparação de comportamento agressivo em meninos e meninas.

Pode-se verificar que somente uma menina apresentou proporção de comportamentos agressivos acima da média dos meninos e que quatro meninos apresentaram proporção de comportamentos agressivos acima da média das meninas. Os dados de comporta- mentos empáticos são complementares e, portanto, nesse caso ocorre exatamente o contrário.

Com relação à faixa etária, a proporção de comportamentos agressivos e empáticos é ilustrada na Figura 3.

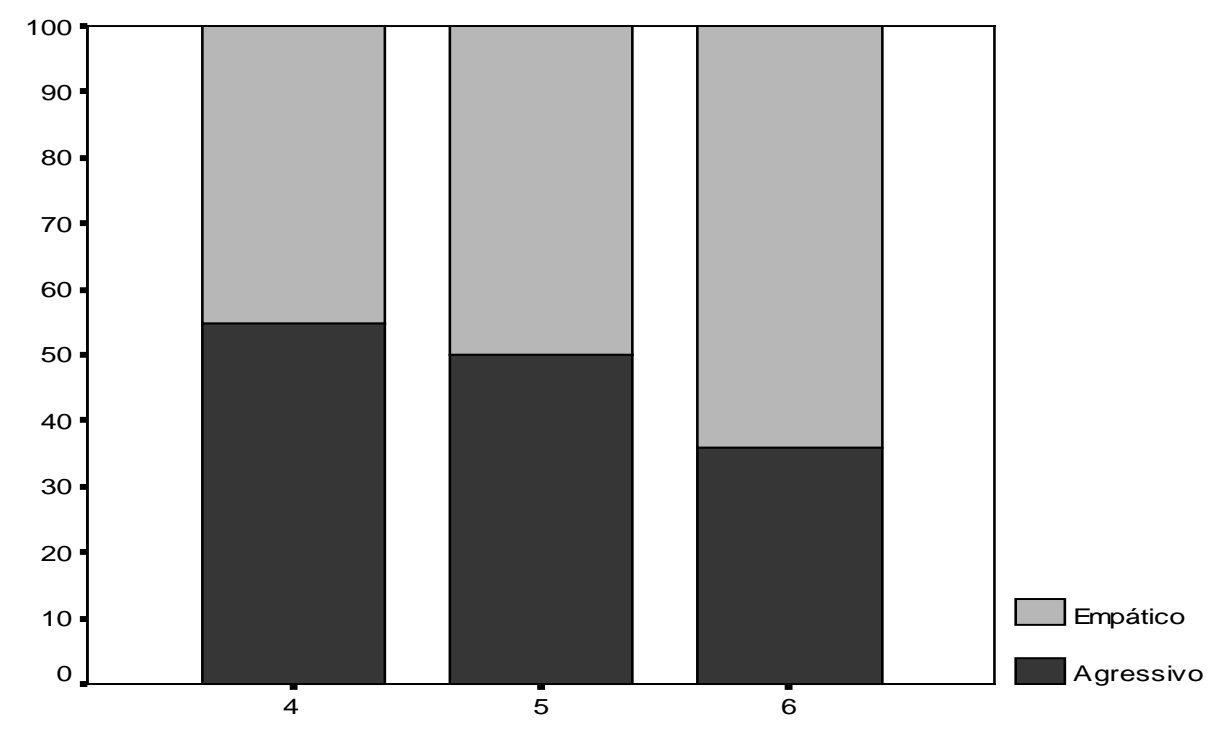

Figura 3. Distribuição da proporção de comportamentos empáticos e agressivos por faixa etária.

A percentagem de comportamento empático e agressivo, ao longo das idades, sugere uma tendência crescente para o primeiro e decrescente para o segundo, mas essas diferenças não se mostraram estatistica- 
mente significativas, embora na faixa dos 6 anos tenha se aproximado da significância (Xagressivo $=4,08 ; \mathrm{dp}=5,25 ;$ Xempático $=7,25 ; \mathrm{dp}=3,91$; $\mathrm{t}=-2,138 ; \mathrm{df}=11 ; \mathrm{p}=0,056)$.

O cruzamento dos dados da frequiência dos comportamentos agressivos com a freqüência dos com- portamentos empáticos, colocando-se os empáticos em ordem crescente, apresentou dados bastante sugestivos sobre a relação dessas duas variáveis associada ao sexo e idade dos participantes, como se pode verificar na Figura 4.

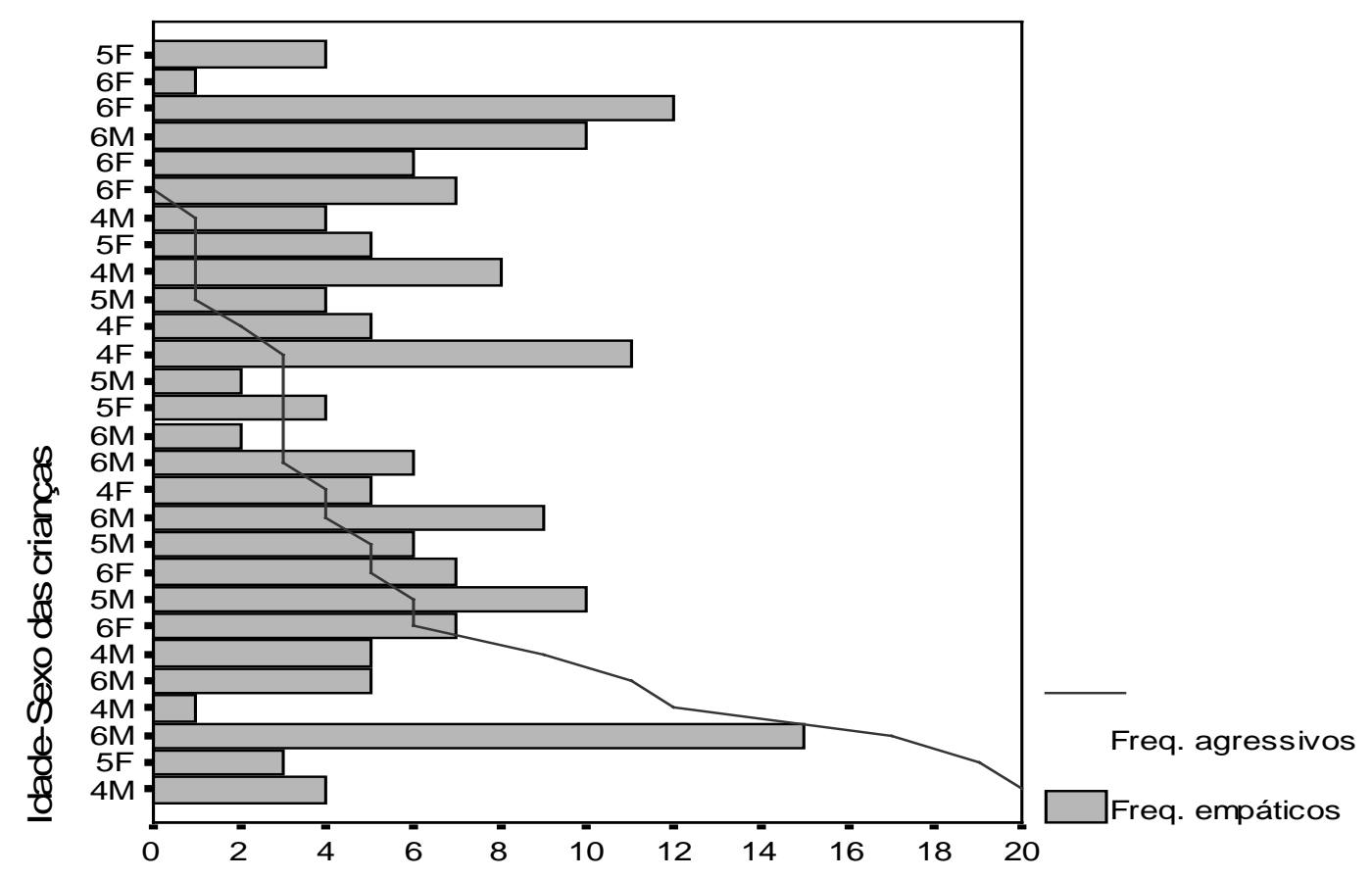

Figura 4. Distribuição da freqüência crescente de comportamentos empáticos em relação à dos comportamentos agressivos na amostra total (no eixo y, o número indica idade e a letra indica o sexo).

Os dados da Figura 4 mostram que seis crianças não apresentaram nenhum comportamento agressivo $\mathrm{e}$ que as seis com maior frequiência de comportamentos agressivos apresentaram taxas reduzidas de comportamento empático, exceto um menino de 6 anos. Entre as crianças que apresentaram até seis ocorrências de comportamento agressivo, somente duas apresentaram taxa inferior de comportamentos empáticos. Como era de se esperar pelos resultados anteriores, a distribuição não sugere tendência associada a sexo e idade.

Uma análise mais descritiva dos comportamentos empáticos e agressivos observados permitiu identificar sete classes do primeiro e nove do segundo. As figuras 5 e 6 ilustram a frequiência com que cada uma das classes apareceu nas diferentes faixas etárias. 


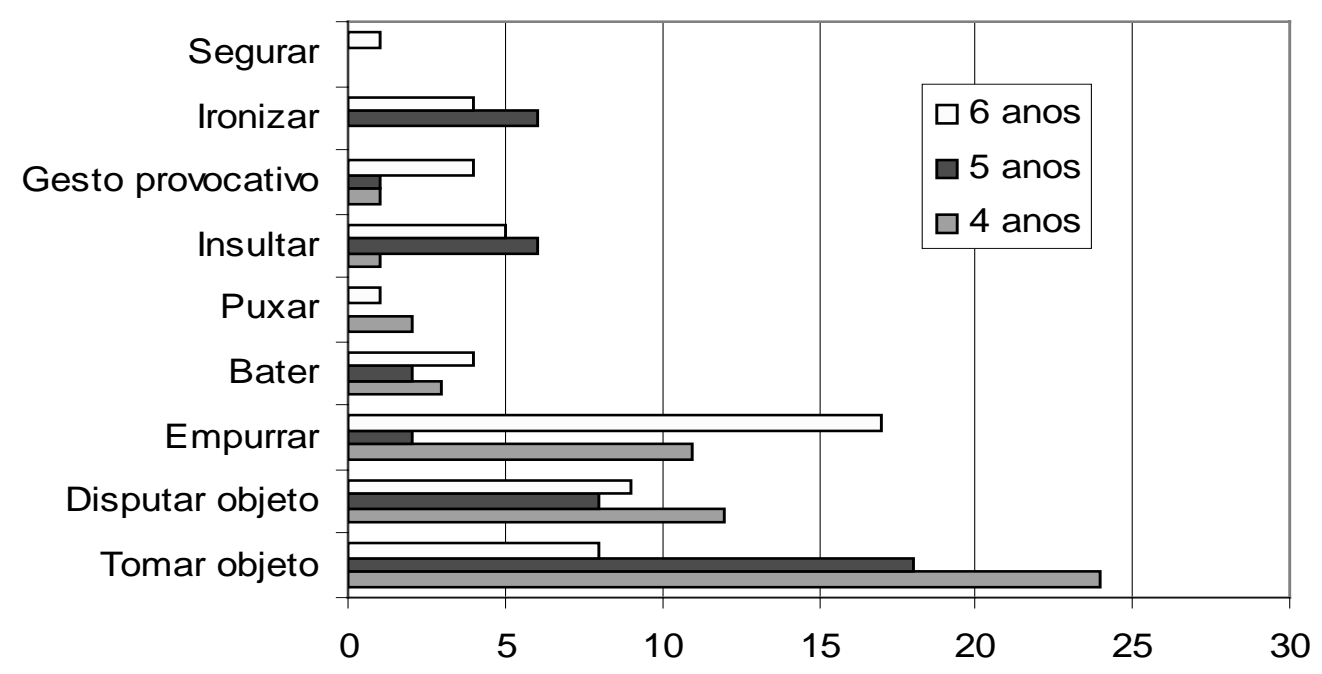

Figura 5. Tipos de comportamentos agressivos por faixa de idade.

Pode-se observar que a classe tomar objeto foi a mais freqüente nas crianças de quatro e cinco anos. Já as crianças com seis anos apresentaram mais freqüentemente o comportamento de empurrar. O que é interessante sublinhar nesse ponto é o fato de que crianças com menos idade apresentaram menor fre- qüência de comportamentos insultar e provocar, enquanto que, nas de maior idade, observou-se uma maior utilização de expressões provocativas, certamente por que já possuem maior domínio da linguagem verbal e assimilação do jargão da subcultura grupal.

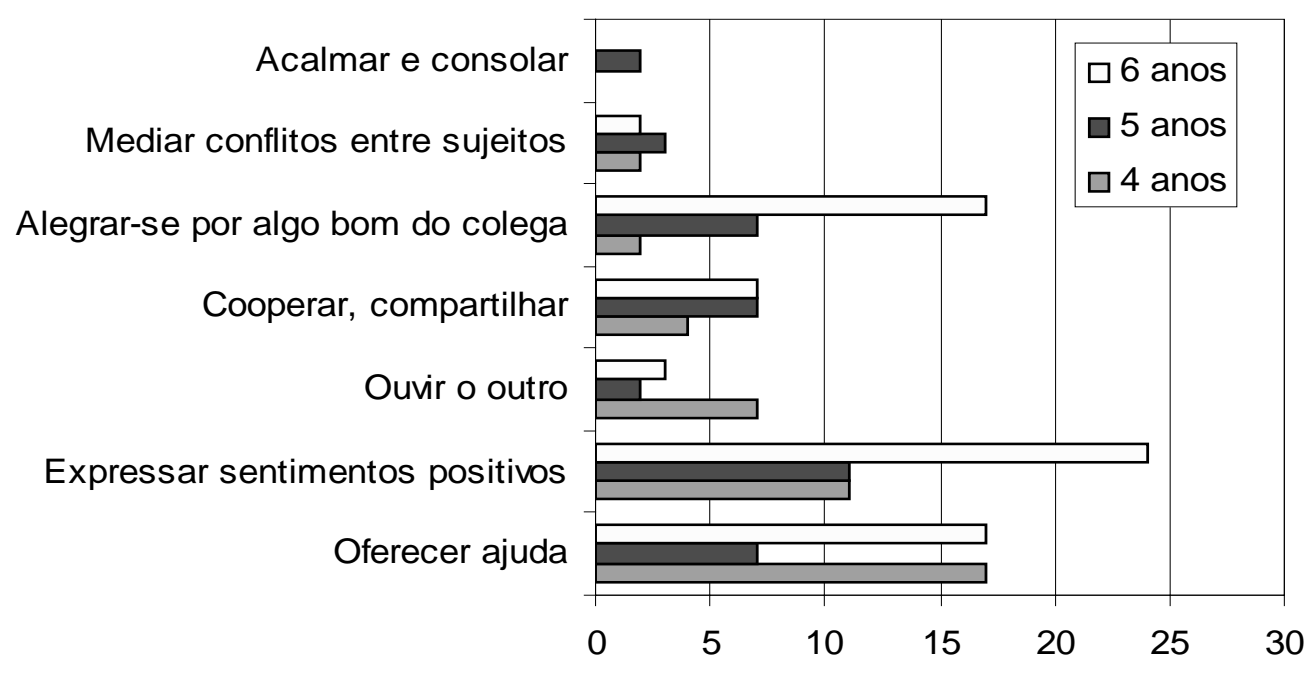

Figura 6. Tipos de comportamentos empáticos por faixa de idade.

Quanto aos comportamentos empáticos, pode-se verificar que os comportamentos de oferecer ajuda incluíam componentes verbais e não verbais e foram apresentados com grande freqüência nas três idades observadas. Verificou-se, também, uma maior freqüência dos comportamentos de alegrar-se por algo bom do colega para a faixa etária de seis anos e de outros comportamentos mais complexos, que exigem comunicação verbal, o que ocorreu com as crianças de seis anos ao expressarem sentimentos positivos.

As análises de correlação entre comportamento empático e agressivo não se mostraram significativas nem para a amostra total nem para as subamostras de sexo e idade. 
Os dados de avaliação dos professores sobre comças por meio do TRF são apresentados na Tabela 2. portamentos problemas de comportamentos das crian-

\begin{tabular}{|c|c|c|c|c|}
\hline Variável & Sexo & $\mathrm{N}$ & Média & D. Padrão \\
\hline \multirow{2}{*}{ Sexo } & Feminino & 13 & 57,77 & 5,20 \\
\hline & Masculino & 15 & 56,40 & 4,48 \\
\hline \multirow{4}{*}{ Idade } & 4 & 8 & 56,13 & 4,02 \\
\hline & 5 & 8 & 55,38 & 3,74 \\
\hline & 6 & 12 & 58,75 & 5,59 \\
\hline & Total & 28 & 57,04 & 4,79 \\
\hline
\end{tabular}

A análise de correlação entre a frequiência de comportamentos agressivos registrados na situação estruturada de vivências e a avaliação de comportamentos agressivos pelo professor, no TRF, não se mostrou significativa nem para a amostra total nem para as subamostras de sexo e idade.

\section{DISCUSSÃO}

Conforme os resultados deste estudo, as crianças apresentaram, em média, uma alta freqüência de comportamentos empáticos e uma frequiência um pouco mais baixa de comportamentos agressivos, mas essas diferenças não se mostraram significativas, possivelmente devido à alta variabilidade no desempenho das crianças. Quando essa diferença foi avaliada em termos de proporção de comportamentos agressivos e empáticos que cada criança apresentou, verificou-se uma tendência de maior proporção de agressivos entre meninos e maior de empáticos entre meninas, o que é coerente com a literatura sobre problemas de comportamento e desenvolvimento socioemocional (Ickes, 1997; Marturano, 1997; Marturano \& Loureiro, 2003; Thompson, 1987).

Observou-se, no entanto, que os resultados deste estudo não confirmaram a hipótese de uma correlação inversa entre comportamento agressivo e empático, contrariando outros estudos nessa área (Covell \& Scarola, 2002; Geer, Estupinan \& Manguno-Mire, 2000). Dadas as condições de coleta de dados, os resultados aqui obtidos sugerem que as crianças dispunham de habilidades empáticas em seu repertório e que, em geral, comportaram-se de acordo com as demandas estabelecidas. Pode-se, portanto, afirmar que as demandas para comportamentos empáticos foram mais efetivas que as demandas para comportamentos agressivos, já que eliciaram maior freqüência de comportamentos. Isso pode estar relacionado à estrutura intrínseca das vivências (em termos de melhor controle de estímulos) ou, talvez, por serem menos co- muns no cotidiano, despertando, então, maior interesse das crianças.

Nesse sentido, o caso mais ilustrativo é, certamente, o do menino de seis anos, que apresentou alta freqüência de comportamentos empáticos e alta freqüência de comportamentos agressivos (Figura 4), sugerindo um controle acentuado da situação e do tipo de demanda sobre seu desempenho. Um dado inesperado, mas que corrobora essa hipótese, foi a falta de diferenciação por sexo na avaliação do professor sobre os problemas de comportamento das crianças (TRF) sugerindo tratar-se de crianças sem queixas nessa área.

A alta freqüência e diversidade de comportamentos empáticos e a falta de correlação entre os resultados da avaliação pelo professor (TRF) e os desempenhos registrados nas situações estruturadas faz supor, ainda, uma possível tendenciosidade na avaliação do professor. E possível que este tenha se baseado muito mais no desempenho usual do aluno diante das demandas do cotidiano escolar do que no desempenho potencial, ou seja, aquilo que a criança é capaz de fazer.

Com relação à idade, verificou-se que a frequiência absoluta não diferenciou as crianças de 4, 5 e 6 anos, porém a proporção de comportamentos empáticos sobre os agressivos foi significativamente maior nas crianças de maior idade do grupo, as de seis anos. Considerando-se que o repertório de habilidades sociais se torna progressivamente mais elaborado com a idade (Del Prette \& Del Prette, 2001; 2005a), esse resultado sugere que essas crianças já apresentam maior capacidade de "leitura" do ambiente social (Argyle, 1967/1994), nesse caso, discriminando as demandas empáticas como socialmente mais valorizadas que as agressivas, nas situações estruturadas pelo pesquisador.

O levantamento dos tipos de comportamentos empáticos e agressivos apresentados pelas crianças permitiu identificar uma diversidade de subclasses. Embora as crianças que se comportam de forma agressiva sejam facilmente reconhecidas por pais e educadores, certamente as crianças que manisfestam empatia podem ser mais sutis e alvo de menor atenção quando 
estes não se mobilizam em favor do desenvolvimento socioemocional de seus filhos ou alunos. O fato constatado de que as reações mais elaboradas parecem se tornar mais freqüentes com a idade sugere a importância e o papel da linguagem que pode ser utilizado tanto para aperfeiçoar comportamentos pró-sociais como anti-sociais. Além disso, certamente a aquisição de maior força física pode contribuir para reações agressivas mais vigorosas se não forem neutralizadas por um aprendizado de respeito e empatia.

Os resultados deste estudo fortalecem a importância do conceito de "demanda" (Del Prette \& Del Prette, 2001) para as pesquisas sobre o repertório de desempenhos sociais em geral, na escola e, em particular, sobre desempenhos de habilidades sociais empáticas. A identificação das demandas está intrinsecamente relacionada à noção de déficit de desempenho (que se caracteriza pela baixa freqüência do comportamento), déficit de aquisição (pela inexistência do comportamento no repertório da criança) e déficit de fluência (pela dificuldade, ansiedade ou custo de resposta na emissão do comportamento), cada um deles com implicações diferentes no contexto escolar (Del Prette \& Del Prette, 2005a; 2005b). O fato de uma criança não apresentar comportamentos empáticos em um determinado contexto pode ser, de forma equivocada, avaliado como déficit de aquisição dessa habilidade quando, efetivamente, o que ocorre é uma escassez de demandas e condições motivacionais para desempenhar as habilidades empáticas de que dispõe.

Considerando que as habilidades sociais são progressivamente aperfeiçoadas com novas aprendizagens, a quantidade de demandas para a competição e a agressividade, mais do que para a cooperação e a empatia, pode restringir o aperfeiçoamento dessas últimas em contexto escolar, transformando os déficits iniciais de desempenho em déficits posteriores de fluência e de aquisição (das mais elaboradas). $\mathrm{O}$ fato de as crianças se comportarem conforme as demandas geradas pelas vivências evidencia a potencialidade destas enquanto procedimento terapêutico/educativo, o que poderia ser mais extensivamente utilizado por educadores para maximizar desempenhos incompatíveis com a agressividade.

Algumas limitações do presente estudo devem ser destacadas. Trata-se de uma amostra pequena e, portanto, com generalização ainda restrita. É possível que os dados de "tendências" pudessem ser melhor avaliados em amostras mais abrangentes. Além disso, pesquisas futuras poderiam comparar desempenhos sociais em situações cotidianas, por exemplo, sala de aula e recreio, ou simular essas observações em situações de vivência desses contextos, porém com outros tipos de demandas comportamentais.

\section{REFERÊNCIAS}

Achenbach, T. M. \& Edelbrock, C. S. (1991). Manual for the child behavior checklist and the revised child behavior profile. Burlington, VT: University Associates in Psychiatry.

Araújo, A. \& Del Prette, A. (2000). Acompanhamento terapêutico e reabilitação psicossocial: resultados de uma pesquisaintervenção. Em Z. A. Trindade \& A. N. Andrade (Orgs.), Psicologia e saúde: Um campo em construção (pp. 101-128). São Paulo: Casa do Psicólogo.

Argyle, M. (1967/1994). Psicologia del comportamiento interpersonal. Madrid: Alianza Universidad.

Bandura, A. (1977). Social learning theory. New Jersey: Prentice Hall.

Bandura, A. (1986). Social foundation of thought and action: a social cognitive theory. New Jersey: Prentice Hall.

Bjoerkqvist, K. \& Oesterman, K. (2000). Social intelligence empathy = aggression? Aggression and Violent Behavior, 5, 191-200.

Brazelton T. B. (1994). Momentos decisivos do desenvolvimento infantil. São Paulo: Martins Fontes.

Caprara, G. V., Barbaranelli, C., Incatasciato, M., Pastorelli, C. \& Rabasca, A. (1997). Emotional instability, physical and verbal aggression, and prosocial behavior as precursors of scholastic achievement and social adjustment. Em S. Feshback \& J. Zagrodzka (Orgs.), Aggression: biological, developmental and social perspectives (pp. 111-120). New York: Plenum Press.

Ciccarone, P. L. (1997). How well do aggressive and rejected children empathize with others? Dissertation Abstracts International: The Sciences and Engineering, 58, 26-67.

Covell, C. N. \& Scarola, M. J. (2002). Empathic deficits in sexual offenders: an integration of affective, social and cognitive constructs. Aggression and Violent Behavior, 7, 251-270.

Del Prette, A. \& Del Prette, Z. A. P. (2001). Psicologia das relações interpessoais: vivências para o trabalho em grupo. Petrópolis: Vozes.

Del Prette, A. \& Del Prette, Z. A. P. (2003). Aprendizagem socioemocional na infância e prevenção da violência: Questões conceituais e metodologia da intervenção. Em A. Del Prette \& Z. A. P. Del Prette (Orgs.), Habilidades sociais, desenvolvimento e aprendizagem: questões conceituais, avaliação e intervenção (pp.82-128). Campinas: Alínea.

Del Prette, Z. A. P. \& Del Prette, A. (1999). Psicologia das habilidades sociais: terapia e educaçâo. Petrópolis: Vozes.

Del Prette, Z. A. P. \& Del Prette, A. (2000). Psicologia das habilidades sociais e dificuldade de aprendizagem: estudos de avaliação. Relatório científico enviado ao CNPq (Processo 523913/96-6). Manuscrito disponível com os autores.

Del Prette, Z. A. P. \& Del Prette, A. (2002). Transtornos psicológicos e habilidades sociais. Em H. J. Guilhardi, M. B. B. B. Madi, P. P. Queiroz \& M. C. Scoz (Orgs.), Sobre comportamento e cognição: contribuições para a construção da teoria do comportamento (pp. 377-386). Santo André: ESETec.

Del Prette, Z. A. P. \& Del Prette, A. (2005a). Psicologia das habilidades sociais na infância: teoria e prática. Petrópolis: Vozes.

Del Prette, Z. A. P. \& Del Prette, A. (2005b). Sistema Multimídia de Habilidades Sociais para Crianças (SMHSC-Del-Prette). São Paulo: Casa do Psicólogo.

Domitrovich, C. F. \& Bierman, K. L. (2001). Parenting practices and child social adjustment: multiple pathways of influence. Merril-Palmer Quarterly, 47, 235-263.

Emery, R. E. (1989). Family violence. Special Issue: Children and their development: knowledge base, research agenda and social police application. American Psychologist, 44, 321-328. 
Falcone, E. (1998). A avaliação de um programa de treinamento da empatia com universitários. Tese de Doutorado. Universidade de São Paulo.

Falcone, E. (2001). A função da empatia na terapia cognitivocomportamental. Em M. L. Marinho \& V. E. Caballo (Orgs.), Psicologia clínica e da saúde (pp. 137-154). Londrina: EDUEL; Granada: APICSA.

Garcia, F. A. (2001). Investigando diferentes indicadores de empatia em meninos e sua relação com a empatia e ações educativas dos pais. Dissertação de Mestrado. Ribeirão Preto: Universidade de São Paulo.

Garcia-Serpa, F. A. G., Meyer, S. B. \& Del Prette, Z. A. P. (2003). Origem social do relato de sentimentos: evidência empírica indireta. Revista Brasileira de Terapia Comportamental e Cognitiva, 5, 21-30.

Geer, J. H., Estupinan, L. A. \& Manguno-Mire, G. M. (2000). Empathy, social skills and other relevant cognitive processes in rapists and child molesters. Aggression and Violent Behavior, 5, 99-126.

Goldstein, A. P. \& Michaels, G. Y. (1985). Empathy: Development, training, and consequences. New Jersey: Lawrence Erlbaum Associates.

Hops, H. (1983). Children's social competence and skills: current research practices and future directions. Behavior Therapy, 14, 3-18.

Ickes, W. (1997). Empathic accuracy. New York: The Guilford Press.

Kazdin, A. E. (1993). Treatment of antisocial behavior in children: current status and future directions. Psychological Bulletin, 102, 187-203.

Kazdin, A. \& Buela-Casal, G. (1997). Conducta antisocial: Evaluación, tratamiento y prevención en la infancia $y$ adolescencia. Madrid: Pirámide.

Main, M. \& George, C. (1985). Responses of abused and disadvantaged toddlers to distress in age mates: a study in day-care setting. Developmental Psychology, 21, 137-161.

Marinho, M. L. (2003). Comportamento anti-social infantil: questões teóricas e de pesquisa. Em A. Del Prette \& Z. A. P. Del Prette (Orgs.), Habilidades sociais, desenvolvimento $e$ aprendizagem: questões conceituais, avaliação e intervenção (pp. 61-82). Campinas: Alínea.

Marturano, E. M. (1997). A criança, o insucesso escolar precoce e a família: condições de resiliência e vulnerabilidade. Em E. M. Marturano, S. R. Loureiro \& A. W. Zuardi (Orgs.), Estudos em saúde mental (pp. 130-149). Ribeirão Preto: CGP em Saúde Mental - FMRP/USP.
Marturano, E. M. \& Loureiro, S. R. (2003). O desenvolvimento socioemocional e as queixas escolares. Em A Del Prette \& Z. A. P. Del Prette (Orgs.), Habilidades sociais, desenvolvimento e aprendizagem: questões conceituais, avaliação e intervenção (pp. 259-292). Campinas: Alínea.

McEvoy, A. \& Walker, R. (2000). Antisocial behavior, academic failure and school climate: a critical review. Journal of Emotional and Behavioral Disorders, 8, 130-140.

Novak, G. (1996). Developmental psychology: Dynamical systems and behavior analysis. New York: Context Press.

Nowicki, S. J. \& Duke, M. P. (1989). A measure of nonverbal social processing ability in children between the ages of 6 and 10. Trabalho apresentado como parte de simpósio na American Psychological Society, Alexandria, VA.

Patterson, G. R., Reid, J. B. \& Dishion, T. J. (1992). Antisocial behavior in children and adolescents: A developmental analysis and model for intervention. Washington: American Psychological Association.

Planalp, S. (1999). Communicating emotion: Social, moral and cultural processes. London: Cambridge University Press.

Roberts, W. \& Strayer. J. (1996). Empathy, emotional expressiveness and prosocial behavior. Child development, 67, 449-470.

Roscoe, C. L. L. (1980). Comportamentos sociais na escola. Em G. S. Morais (Org.), Pesquisa e realidade no ensino de primeiro grau. São Paulo: Cortez.

Thompson, R. A. (1987). Empathy and emotional understanding: the early development of empathy. Em E. N. Eisenberg \& J. Strayer (Orgs.), Empathy and its development (pp. 119-145). New York: Cambridge University Press.

Walker, H. M. \& Severson, H. H. (2002). Developmental prevention of at-risk outcomes for vulnerable antisocial children and youth. Em K. L. Lane, F. M. Gresham \& T. E. O'Shaughnessy (Orgs.), Children with or at risk for emotional and behavioral disorders (pp. 177-194). Boston: Allyn \& Bacon.

Walker, H. M. \& Sprague, J. R. (1999). The path to school failure in delinquency and violence: casual factures and some potential solutions. Intervention in School and Clinic, 35, 67-73.

Walker, H. M., Colvin, G. \& Ramsey, E. (1995). Antisocial behavior in school: Strategies and best practices. Pacific Grove: Brooks Cole.

Recebido: 30/05/2005 Revisado: 02/11/2005 Aceito: 19/11/2005

\section{Nota:}

1 Este artigo é derivado de parte da Dissertação de Mestrado da primeira autora (Pavarino, 2004) sob a orientção do segundo autor. Esta reelaboraçã̃o contou com a participação da terceira autora.

\section{Sobre os autores:}

Michelle Girade Pavarino: Psicóloga e Mestra em Educação Especial pela Universidade Federal de São Carlos.

Almir Del Prette e Zilda A. P. Del Prette: Professores Doutores Titulares do Departamento de Psicologia da Universidade Federal de São Carlos e integrantes do Programa de Pós-Graduação em Educação Especial (UFSCar) e do Programa de Pós-Graduação em Psicologia (USP-Ribeirão Preto). Homepage: www.rihs.ufscar.br; E-mail: zdprette@ power.ufscar.br e adprette@ power.ufscar.br.

Endereço para correspondência: Universidade Federal de São Carlos - Centro de Educação e Ciências Humanas- CECH - Departamento de Psicologia - Laboratório de Interação Social - LIS - Via Washington Luís, km 235. Caixa Postal, 676. CEP 13565-905 - São Carlos - SP 